\title{
Identifying the prognostic significance of B3GNT3 with PD-L1 expression in lung adenocarcinoma
}

\author{
Xuefeng Leng ${ }^{1,2 \#}$, Shiyou Wei ${ }^{1 \#}$, Jiandong Mei ${ }^{1 \#}$, Senyi Deng ${ }^{1}$, Zhenyu Yang ${ }^{1}, Z_{\text {Zheng Liu }}{ }^{1}$, Chenglin Guo ${ }^{1}$, \\ Yulan Deng ${ }^{1}$, Liang Xia ${ }^{1}$, Jiahan Cheng ${ }^{1}$, Kejia Zhao ${ }^{1}$, Fanyi Gan ${ }^{1}$, Chuan Li $^{1}$, Kenneth W. Merrell ${ }^{3}$, \\ Julian R. Molina ${ }^{4}$, Giulio Metro ${ }^{5}$, Lunxu Liu ${ }^{1}$ \\ ${ }^{1}$ Department of Thoracic Surgery, Institute of Thoracic Oncology/West China Hospital, Sichuan University, Chengdu, China; ${ }^{2}$ Division of Thoracic \\ Surgery, Sichuan Cancer Hospital \& Institute, School of Medicine, University of Electronic Science and Technology of China (UESTC), Chengdu, \\ China; ${ }^{3}$ Department of Radiation Oncology, Mayo Clinic, Rochester, MN, USA; ${ }^{4}$ Division of Medical Oncology and Molecular Medicine, Mayo \\ Clinic, Rochester, MN, USA; ${ }^{5}$ Medical Oncology, Santa Maria della Misericordia Hospital, Azienda Ospedaliera di Perugia, via Dottori, 1, 06156, \\ Perugia, Italy \\ Contributions: (I) Conception and design: J Mei, S Deng, L Liu; (II) Administrative support: J Mei, L Liu; (III) Provision of study materials or \\ patients: X Leng, S Wei, J Mei, S Deng, Z Yang, Z Liu, C Guo, Y Deng, L Xia, J Cheng, K Zhao, F Gan, C Li; (IV) Collection and assembly of data: \\ X Leng, S Wei, J Mei; (V) Data analysis and interpretation: X Leng, S Wei, J Mei, Z Yang, Y Deng; (VI) Manuscript writing: All authors; (VII) Final \\ approval of manuscript: All authors. \\ "These authors contributed equally to this work. \\ Correspondence to: Lunxu Liu. Department of Thoracic Surgery, Institute of Thoracic Oncology/West China Hospital, Sichuan University No.37, \\ Guoxue Alley, Chengdu 610041, China. Email: lunxu_liu@aliyun.com.
}

Background: As a novel treatment, programmed cell death protein 1 (PD-1) inhibitor appears to be less effective in tumors of lung adenocarcinoma patients with epidermal growth factor receptor (EGFR) mutation. Beta-1,3-N-acetylglucosaminyltransferase 3 (B3GNT3) has reported to be associated with programmed death ligand 1 (PD-L1)/PD-1 interaction. However, the relationship between B3GNT3 and PD-L1 and its prognostic significance in EGFR-mutant status are still unknown.

Methods: B3GNT3 was identified through transcriptome sequencing and The Cancer Genome Atlas Lung Adenocarcinoma (TCGA-LUAD) database. Flow cytometry and real-time polymerase chain reaction were performed to investigate the association between B3GNT3, PD-L1, and EGFR. Then, B3GNT3 and PD-L1 expression were evaluated by immunohistochemical analysis in 145 surgically resected primary lung adenocarcinomas. The relationships between survival and B3GNT3, PD-L1, and EGFR status were assessed, and the potential prognostic factors in patients with B3GNT3 expression were identified.

Results: We found that EGFR activation induced PD-L1 expression, and EGFR tyrosine kinase inhibitor (TKI) could reduce PD-L1 protein in EGFR-TKI-sensitive HCC827 and PC9 cell lines. Subsequent analysis showed that EGFR inhibitor could also lead to both decreased PD-L1 and B3GNT3 mRNA expression. A total of 145 lung adenocarcinoma patients were included. PD-L1 >1\% and B3GNT3-positive expression in patients might contribute to worse prognosis in both overall survival (OS) [hazard ratio (HR), 2.63; 95\% confidence interval (CI), 0.98-7.06; $\mathrm{P}=0.048$ ] and disease-free survival (DFS) (HR, 3.04; 95\% CI, 1.13-8.14; $\mathrm{P}=0.019$ ), especially in the PD-L1 $\geq 50 \%$ group. However, when patients were negative for B3GNT3, PD-L1, and EGFR (or “triple negative"), there were significant decreases in OS (HR, 5.44; 95\% CI, 0.99-29.83; P=0.029) and DFS (HR, 7.24; 95\% CI, 1.32-39.73; P=0.008). Positive B3GNT3 expression was a significant risk factor associated with lower DFS (HR, 3.30; $\mathrm{P}=0.043)$.

Conclusions: Our results indicate that the B3GNT3 expression is tightly correlated with PD-L1 expression and EGFR mutation status. B3GNT3 is associated with poor prognosis in lung adenocarcinoma patients. Collectively, these findings may offer new insight into enhancing immune therapy efficacy for lung adenocarcinoma patients. 


\begin{abstract}
Keywords: Beta-1,3-N-acetylglucosaminyltransferase 3 (B3GNT3); programmed cell death protein 1 (PD-1);
\end{abstract} epidermal growth factor receptor (EGFR); lung adenocarcinoma

Submitted Nov 13, 2020. Accepted for publication Feb 24, 2021.

doi: $10.21037 /$ tlcr-21-146

View this article at: http://dx.doi.org/10.21037/tlcr-21-146

\section{Introduction}

The total number of lung cancer survivors continues to increase due to advancements in early detection and treatment. However, there were still an estimated 228,150 diagnosed lung cancer cases $(116,440$ in males and 111,710 in females) and 142,670 deaths (76,650 in males and 66,020 in females) in the United States in 2019 (1). Overall, patients treated with targeted therapy drugs, such as different generations of epidermal growth factor receptor (EGFR) inhibitors or immunotherapies, are now surviving longer $(2,3)$.

Several predictive and prognostic biomarkers for nonsmall cell lung cancer (NSCLC) have emerged. For instance, the presence of EGFR exon 19 deletions (19dels) or exon 21 L858R mutations could benefit from EGFR tyrosine kinase inhibitor (EGFR-TKI) treatment (e.g., gefitinib) (4). Programmed death ligand 1 (PD-L1; also known as B7-H1) in cancer cells interacts with programmed cell death protein 1 (PD-1), enabling cancer cells to escape T cell-mediated immune surveillance (5). Immune checkpoint inhibitor antibodies, which inhibit the $\mathrm{PD}-1$ receptor or $\mathrm{PD}-\mathrm{L} 1$, improve antitumor immunity (6). PD-L1 expression is thus currently the best available biomarker to assess whether patients are candidates for PD-1 or PD-L1 inhibitors, but even PD-L1 is not an optimal biomarker (7). Regardless of PD-L1 expression levels, subsequent therapy with a singleagent PD-1 or PD-L1 inhibitor appears to be less efficacious in tumors with EGFR mutations, based on data in the second-line setting (8-10). This also suggests that singleagent immunotherapy is not effective as first-line therapy in patients with metastatic NSCLC and EGFR mutations, even those with PD-L1 proportions greater than 50\% (11). Thus, identifying new biomarkers relevant to immune check-point targets and improving the efficacy of PD-1/PDL1 blockade therapy in EGFR-mutated/non-mutated lung adenocarcinoma is urgently needed.

Beta-1,3-N-acetylglucosaminyltransferase 3 (B3GNT3) is a type II transmembrane protein located in the Golgi apparatus. It participates in the biosynthesis of poly-Nacetyllactosamine chains, the generation of the backbone components of dimeric sialyl Lewis A, and the regulation of L-selectin ligand function, lymphocyte trafficking, and T cell homing $(12,13)$. The B3GNT3 gene is located on chromosome $19 \mathrm{q} 13.1$ and belongs to the $\beta 3$ GlcNAcT gene family, which includes at least eight distinct $\beta 3$ GlcNAcTs. The 33 GlcNAcT family members are closely correlated with the development and progression of malignancies (14). For example, EGFR has been shown to stabilize PD-L1 in basal-like breast cancer, and gefitinib-inhibited EGFR signaling can destabilize PD-L1 and enhance antitumor T-cell immunity, thus elevating the therapeutic efficacy of PD-1 blockade (15). The glycosylation pathway may also be linked to the regulation of $\mathrm{PD}-\mathrm{L} 1$ as there appears to be a higher expression of glycosyltransferase B3GNT3 in breast cancer tissues, suggesting that B3GNT3-mediated glycosylation PD-L1 may contribute to cancer development (15). As the EGFR/B3GNT3/gPD-L1 axis is upregulated in tumor cells, glycosylation of PD-L1 antibody might increase target specificity and reduce the off-target effects (16).

Very little data is available regarding B3GNT3 expression and cancer outcomes though one study suggests an association with unfavorable disease-free survival (DFS) and overall survival (OS) in NSCLC patients with high levels of expression (17). However, no data is available on the impact B3GNT3 and PD-L1 expression in EGFRmutated lung adenocarcinoma. This study therefore aimed to understand the association and impact of B3GNT3 on PD-L1 expression through the EGFR/B3GNT3/PD-L1 axis. We present the following article in accordance with the REMARK reporting checklist (available at http://dx.doi. org/10.21037/tlcr-21-146).

\section{Methods}

\section{Cell lines and culture}

Human lung adenocarcinoma EGFR mutation cell lines H1975 $\left({\mathrm{L} 858 \mathrm{R}^{+} \text {and T790M }}^{+}\right), \mathrm{HCC}_{2} 7\left(19 \mathrm{del}^{+}\right)$, PC9 $\left(19 \mathrm{del}^{+}\right)$, and EGFR-wildtype cell line A549 were purchased from the American Type Culture Collection (ATCC, Manassas, VA, USA). Cell lines were cultured in RPMI 
1640 medium (Gibco, Thermo Fisher Scientific, USA) plus $10 \%$ heat-inactivated fetal bovine serum (FBS) at $37{ }^{\circ} \mathrm{C}$ in a humidified atmosphere of $5 \% \mathrm{CO}_{2}$ and $95 \%$ air. MTT colorimetry was used to detect the growth of EGFR-TKI (gefitinib, no. 13166, Cayman Chemical, Ann Arbor, MI, USA) treated lung adenocarcinoma cells. HCC827, PC9, H1975 and A549 cell lines were treated with different concentration gradients of Gefitinib $(0.01-10 \mu \mathrm{mol} / \mathrm{L})$, in order to determine the sublethal dose of gefitinib for the next step analysis.

Gefitinib-treated and untreated cells were stained with anti PD-L1 antibody (\#13684, Cell Signaling Technology, Danvers, MA, USA) and isotype control (BioLegend, San Diego, CA, USA) to analyze PD-L1 expression. PDL1 levels were detected by using a Beckman Coulter CytoFLEX flow cytometer (CytExpert software, Beckman Coulter, Brea, CA, USA). Graphical output and the analysis were performed by Flowjo software (Tree Star, USA).

\section{Reverse transcription polymerase chain reaction (RT-PCR)}

Total RNA was isolated from cell culture $\left(1 \times 10^{6}\right.$ cells $)$ using Trizol reagent (Invitrogen, Thermo Fisher Scientific, USA) following the manufacturer's protocol. Then, $2 \mu \mathrm{L}$ of total RNA was reverse transcribed with oligo (dT) 18 by using ReverTra Ace kit (BioBRK Co., Chengdu, China), and $2 \mu \mathrm{L}$ of cDNA was amplified by using Taq DNA Polymerase Kit (BioBRK Co.). Reverse transcription polymerase chain reaction (RT-PCR) was performed with the following primers. GAPDH forward primer: 5'-TGCACCACCAACTGCTTAGC-3'; GAPDH reverse primer: 5'-GGCATGGACTGTGGTCATGAG-3'; PD-L1 forward primer: 5'-GGTGCCGACTACAAGC GAAT-3', PD-L1 reverse primer: 5'-GGTGACTG GATCCACAACCAA-3'; B3GNT3 forward primer: 5'TCTTCAACCTCACGCTCAAG-3', B3GNT3 reverse primer: 5'-GTGTGCAAAGACGTCATCATC-3'.

The PCR conditions were as follows: pre-denaturation at $95^{\circ} \mathrm{C}$ for $5 \mathrm{~min} ; 35$ cycles of amplification at $95^{\circ} \mathrm{C}$ for $15 \mathrm{~s}$, $56{ }^{\circ} \mathrm{C}$ for $45 \mathrm{~s}$, and $72{ }^{\circ} \mathrm{C}$ for $45 \mathrm{~s}$; and extension at $72{ }^{\circ} \mathrm{C}$ for $5 \mathrm{~min}$. GAPDH was used as an internal control.

\section{Bioinformatic analysis}

Download TCGA expression data and survival data through FireHouse by using FireBrowse (http://firebrowse. org/). Download the closely related genes to survival in the O-linked glycosylation family from the MGSigDB database (http://www.gsea-msigdb.org/gsea/msigdb/index. jsp) and use the "survMisc" in the R language to select gene expression. Use the COX hazard proportional regression model to compare the hazard ratio (HR) value and $95 \%$ confidence interval (CI) of high/low gene expression. Transcriptome sequencing was performed on the PC9 cell line before and after Gefitinib treatment, HISAT software was used for comparison, Stringtie software was used for assembly, and DEseq2 software was used for difference comparison. The corrected $\mathrm{P}_{\text {adj }}<0.05$ was selected as the significantly changed gene, and $\mathrm{R}$ drew heat maps for differential genes. Use the R packages 'survival', 'survminer' to compare the relationship between B3GNT3 expression and TCGA-LUAD progression-free survival (PFS) and overall survival (OS) and perform COX multifactorial regression analysis comparing the relationship between survival and other important clinical prognostic factors.

\section{Immunobistochemical (IHC) staining of human tumor tissues}

IHC staining was performed according to the manufacturer's instructions. Tissue specimens were incubated with antibodies against PD-L1 (dilution, 1:200, \#13684, Cell Signaling Technology) or B3GNT3 (dilution, 1:100, \#18098-1-AP, Proteintech) and a biotin-conjugated secondary antibody, and then incubated with an avidinbiotin-peroxidase complex. Phosphate-buffered saline (PBS) was used as the negative control at the same dilutions, and 3,3'-diaminobenzidine (DAB) was used to visualize the reaction products. According to histologic scoring, the expression of PD-L1 was determined by the tumor proportion score (TPS) criterion, which is the percentage of tumor cells with partial or complete cell membrane staining at any intensity. PD-L1 expression was divided into three clinically relevant categories: TPS $<1 \%$, TPS $1-49 \%$, or TPS $\geq 50 \%$, based on five random areas at $200 \times$ magnification on each slide (18). The staining intensity (SI) of B3GNT3 was ranked into one of four groups: high (score 3), medium (score 2), low (score 1), or negative (score 0 ). The total percentage of positive cells (PP) was ranked into $0 \%$ (score 0 ), $1-10 \%$ (score 1 ), $11-30 \%$ (score 2), 31-50\% (score 3), or $>50 \%$ (score 4). The expression of B3GNT3 was scored using the SI multiplied by PP scores. It was categorized as negative expression (-, score 0$)$, weak expression (1+, score 1-4), moderate expression (2+, score 5-8), and strong expression (3+, score 9-12). Samples were dichotomized to either negative B3GNT3 expression (- in 
A

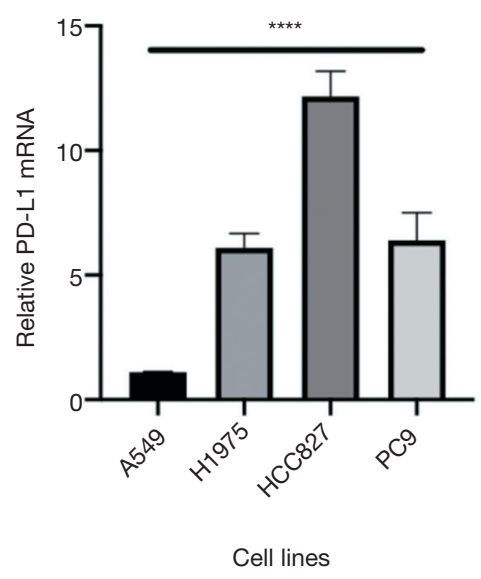

B
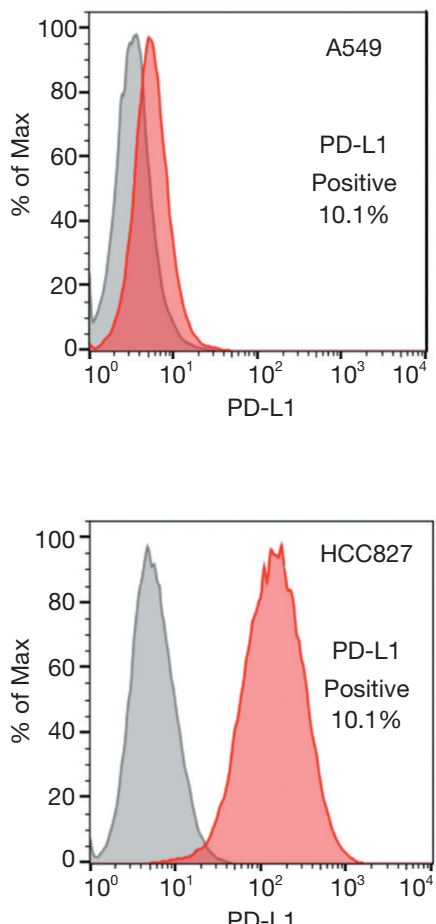

C

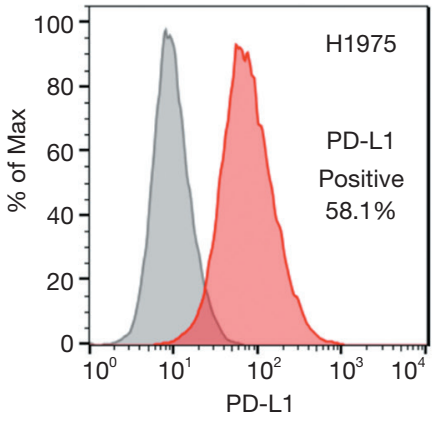

E

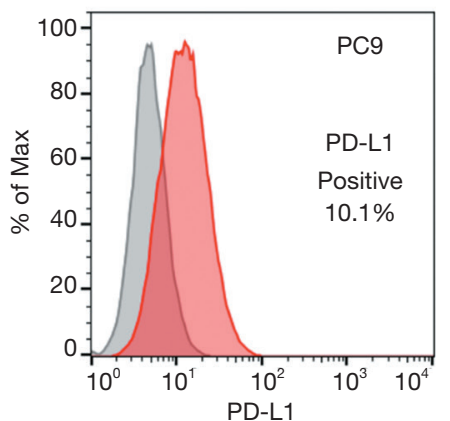

Figure 1 PD-L1 expression in human lung adenocarcinoma cell lines with or without EGFR mutation. RT-PCR (A) and flow cytometry (B,C,D,E) analysis of PD-L1 expression in A549, H1975, HCC827, and PC9 cell lines. ${ }^{* * * *} \mathrm{P}<0.0001$. PD-L1, programmed cell deathligand 1; RT-PCR, reverse transcription polymerase chain reaction; EGFR, epidermal growth factor receptor.

immunoreactivity) or positive B3GNT3 expression (1+, 2+, or $3+$ in immunoreactivity) (19). For discrepant results a consensus pathologists' determination was required.

\section{Statistical analysis}

Statistical analyses were performed using SPSS v26.0 (IBM Corp., Armonk, NY, USA) and GraphPad Prism 8.0 Software (San Diego, CA, USA). A two-sample $t$-test was used for continuous variables. The correlation between biomarker expression and clinicopathological characteristics was evaluated using the $\chi^{2}$ test. Pearson's correlation was used to study the correlation between different biomarker expression. Overall survival (OS) was defined as the time from treatment until the time of death by any cause or the time that the patient was last known to be alive. Disease-free survival (DFS) was defined as the time from treatment to the time of first recurrence or metastasis or the last followup. OS and DFS were calculated by Kaplan-Meier method, and the differences in survival curves were examined using the log-rank test. Cox proportional hazards regression model was used to conduct univariate and multivariate analyses. All analyses were two sided with an alpha value of 0.05 as the significance level.

\section{Results}

\section{EGFR mutation and association with PD-L1 in buman lung adenocarcinoma cells}

To investigate if mutant EGFR is able to induce PDL1 expression in lung adenocarcinoma, we tested PDL1 expression in human lung adenocarcinoma cell lines, specifically with the EGFR mutations, H1975, HCC827, and PC9. We observed a significantly higher PD-L1 expression with EGFR-mutated compared to non-EGFRmutated A549 cell lines $(\mathrm{P}<0.0001, \mathrm{~F}=95.12)$ (Figure 1A). Flow cytometry confirmed the high PD-L1 expression at the protein level in EGFR mutant cell lines compared to A549 cell lines (Figure 1B,C,D,E). This suggested that oncogenic $E G F R$ mutations in lung adenocarcinoma cell lines could drive PD-L1 upregulation, and the expression profiling of the EGFR signaling pathway seemed to positively regulate PD-L1 expression in human lung adenocarcinoma cell lines. 
A

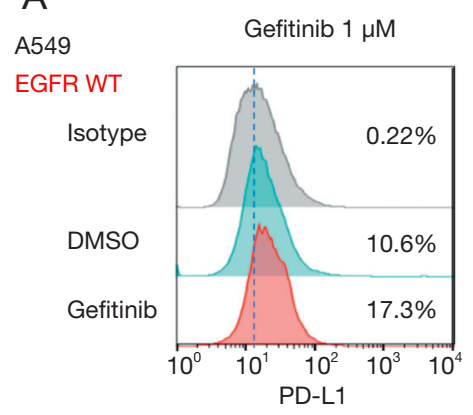

C

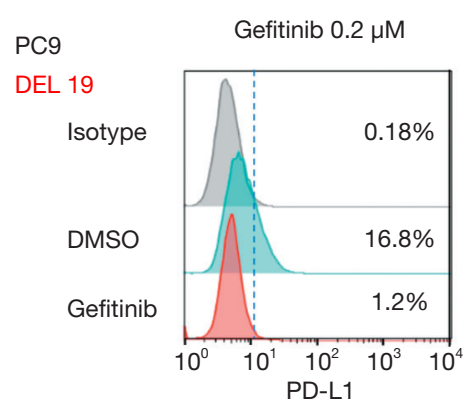

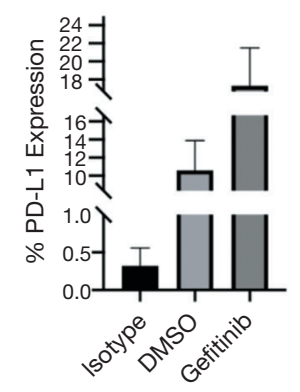

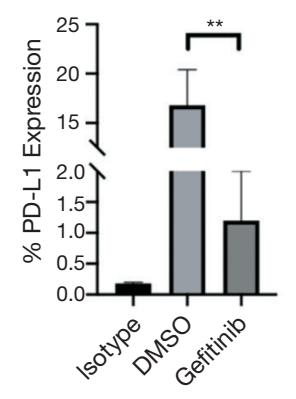

B
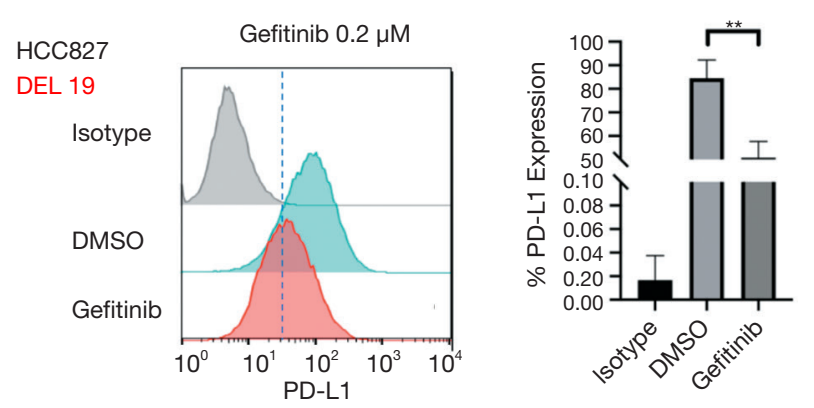

D

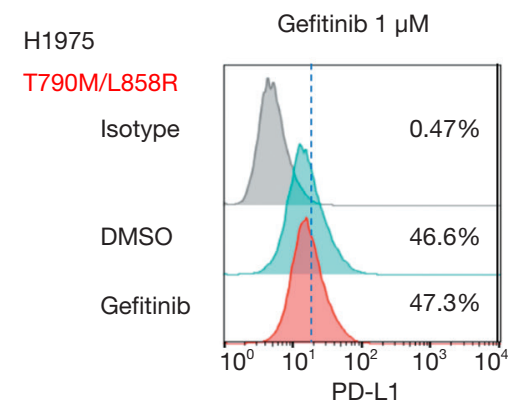

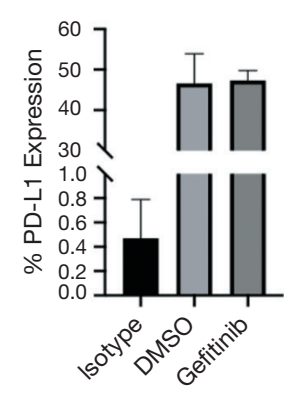

Figure 2 Gefitinib regulates PD-L1 expression in different lung adenocarcinoma cell lines. Flow cytometry analysis of PD-L1 expression in A549 cell lines (A), HCC827 cell lines (B), PC9 cell lines (C), and H1975 cell lines (D). ** $\mathrm{P}<0.01$. PD-L1, programmed cell death-ligand 1; DMSO, dimethyl sulfoxide.

\section{EGFR pathway activation correlated with PD-L1 expression across lung adenocarcinoma cell lines}

The EGFR tyrosine kinase inhibitor (TKI), gefitinib, was used at a sublethal dose in order to evaluate the levels of PD-L1 expression in EGFR mutant cell lines after treatment. Flow cytometry showed Gefitinib did not decrease PD-L1 levels in the EGFR wild-type A549 cell lines or the gefitinib-resistant H1975 cell lines, but did do so in the gefitinib-sensitive EGFR-mutated cell lines. An apparent reduction of PD-L1 observed in EGFR-TKIsensitive HCC827 and PC9 cell lines (Figure 2A,B,C,D). A dependent correlation between EGFR signaling and PD-L1 expression was confirmed, which indicated that the related EGFR pathway activation of the EGFR mutation may also induce the expression of PD-L1.

\section{B3GNT3 correlated with PD-L1 expression in EGFR mutation NSCLC cell lines}

To further explore the changes of expression of the other genes correlated with PD-L1 in EGFR mutation cell lines, transcriptome sequencing was performed for PC9 cell lines with treatment of sublethal doses of gefitinib. Interestingly, after the intervention of gefitinib, the heatmap showed an obvious decrease of B3GNT3 mRNA expression accompanied by PD-L1 (CD274) (Figure 3A). In order to verify the results from this bioinformatic analysis, we first performed a quantitative PCR (qPCR) analysis of B3GNT3 in the same cell lines that the PD-L1 expression was tested. It showed that B3GNT3 was specifically upregulated in three EGFR-mutated NSCLC cell lines compared to A549: H1975, HCC827, and PC9. We observed a strong correlation between B3GNT3 and EGFR gene mutation $(\mathrm{P}<0.0001, \mathrm{~F}=455.6)$ (Figure 3B). Moreover, analysis based on The Cancer Genome Atlas Lung Adenocarcinoma (TCGA-LUAD) database also indicated there was a significant correlation between the expression of B3GNT3 and survival (Figure 3C,D), suggesting that EGFR may have a close correlation with B3GNT3.

To evaluate whether the PD-L1 could be a candidate regulator of B3GNT3 expression, we next treated EGFRmutated cell lines with sublethal doses of the gefitinib at the 


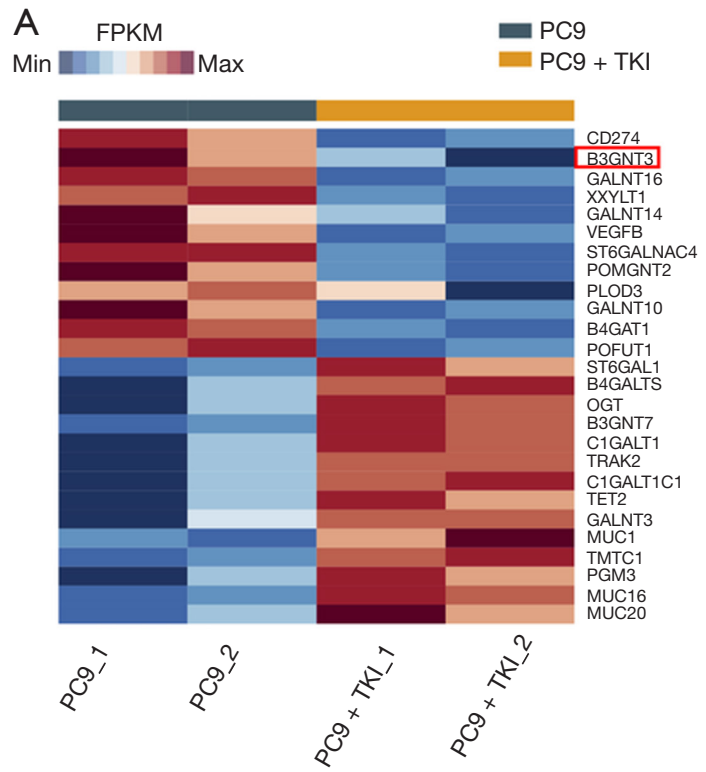

C

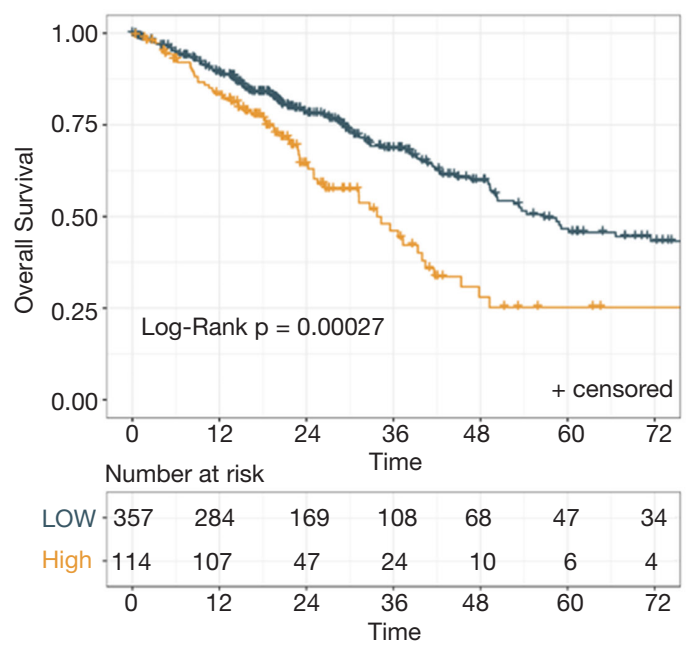

B

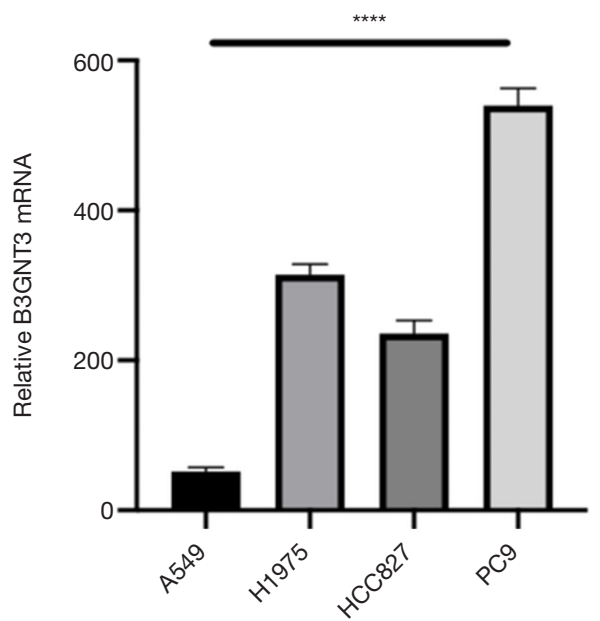

Cell lines

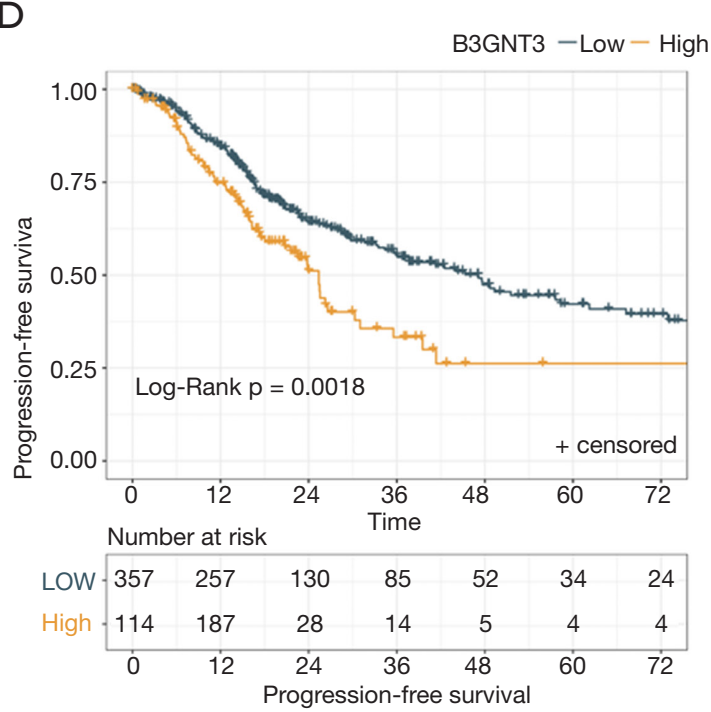

Figure 3 Identification of B3GNT3 in lung adenocarcinoma cell lines. (A) Heatmap of transcriptome sequencing of lung adenocarcinoma PC9 cell lines and identification of B3GNT3. (B) RT-PCR analysis of B3GNT3 expression in A549, H1975, HCC827, and PC9 cell lines. Kaplan-Meier analysis of OS (C) and PFS (D) according to B3GNT3 expression in lung adenocarcinoma based on TCGA-LUAD database. ${ }^{* * * *} \mathrm{P}<0.0001$. B3GNT3, beta-1,3-N-acetylglucosaminyltransferase 3; TCGA-LUAD, The Cancer Genome Atlas Lung Adenocarcinoma; OS, overall survival; PFS, progression-free survival; RT-PCR, reverse transcription polymerase chain reaction.

point of 8, 12, 24, 48 hours. qPCR analysis indicated that EGFR inhibitor caused significantly decreased PD-L1 and B3GNT3 mRNA expression (Figure 4A,B). This positive association between B3GNT3 and PD-L1 was confirmed in the Molecular Signatures Database (MSigDB) and TCGALUAD databases. Taken together, our analysis indicated that B3GNT3 is closely correlated with PD-L1 expression in EGFR-mutated NSCLC cells lines.

\section{Association between PD-L1 and B3GNT3 expression in lung adenocarcinoma}

In addition to analyzing PD-L1 and B3GNT3 expression in cell lines, a total of 145 archived, paraffin-embedded, lung adenocarcinoma slides were obtained from West China Hospital between June 2013 and January 2018. We used IHC to investigate their protein level in a retrospective 

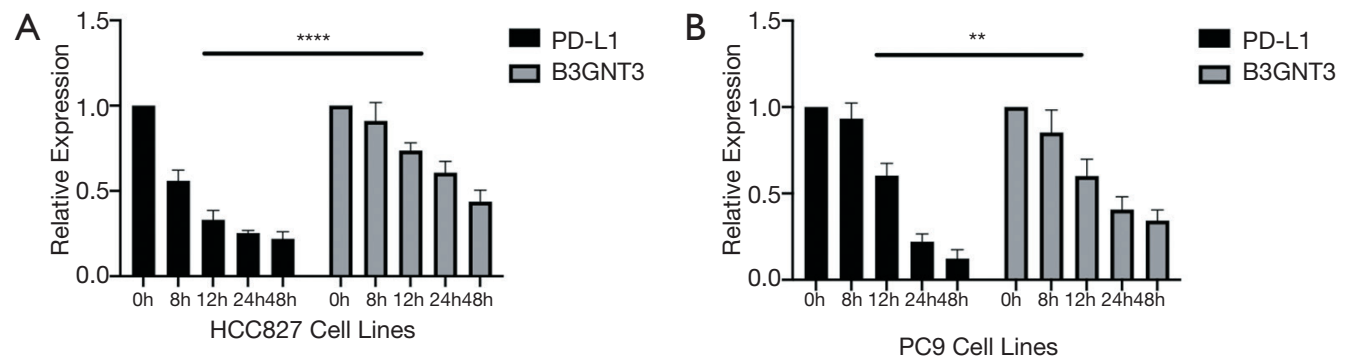

Figure 4 Association between PD-L1 and B3GNT3 expression in EGFR-TKI-sensitive HCC827 (A) and PC9 cell lines (B) by 48 hours continuous intervention of gefitinib. ${ }^{* *} \mathrm{P}<0.01$, ${ }^{* * *} \mathrm{P}<0.0001$. PD-L1, programmed cell death-ligand 1; B3GNT3, beta-1,3-Nacetylglucosaminyltransferase 3; EGFR-TKI; epidermal growth factor receptor tyrosine kinase inhibitor

cohort of 145 lung adenocarcinoma samples obtained from patients who underwent surgery (Figure 5). None of the patients received neoadjuvant therapy before surgery. Our Institutional Ethics Committee waived the requirement for informed consent due to the retrospective design of the study. The diagnosis of all patients was histopathologically confirmed, and the clinical characteristics of all patients are summarized in Table 1.

The median age of the 145 patients was 61 years, with a range from 28 years to 84 years. Seventy-seven $(53.1 \%)$ of the patients were female, and 68 (46.9\%) were male. As indicated by IHC, PD-L1 protein expression was located in the cellular membrane, while B3GNT3 protein expression was mainly located in the cytoplasm. The relationships between PD-L1 and B3GNT3 expression in different clinicopathological variables are shown in Table 1.

Further molecular analysis revealed 51 non-EGFRmutated cases and 94 cases with EGFR mutations inclusive of EGFR 19dels ( $\mathrm{n}=44)$, EGFR exon 21 L858R ( $\mathrm{n}=49$ ), and one patient with an unknown mutation. A total of 106 (73.1\%) cases were negative for PD-L1 expression $(<1 \%)$ and 39 cases were positive for PD-L1 expression $(>1 \%)$, in which 30 cases $(20.7 \%)$ showed strong PD-L1 expression $(\geq 50 \%)$. Of the 94 patients with EGFR-mutations, 24 had positive PD-L1 expression (>1\%) compared to 15 of the 51 non-EGFR-mutated patients with positive PD-L1 expression. EGFR mutations were significantly associated with both no expression (PD-L1 $<1 \%$ ) and high expression category (PD-L1 $\geq 50 \%)(\mathrm{P}=0.043)$.

We next analyzed the association between specific EGFR mutations and the level of PD-L1 expression. In patients with EGFR $19 \mathrm{del}$ mutations, $69.8 \%$ (30/43) of cases had PD-L $1<1 \%$ and $30.2 \%(13 / 43)$ cases had PD-L1 $\geq 50 \%$ ( $\mathrm{P}=0.028)$. In patient with EGFR exon $21 \mathrm{~L} 858 \mathrm{R}$ mutations, 90.7\% (39/43) of cases had PD-L1 <1\% and 9.3\% (4/43) cases had $\mathrm{PD}-\mathrm{L} 1 \geq 50 \%(\mathrm{P}=0.028)$. In patients with both EGFR-mutations PD-L1 TPS >1\%, 92.9\% (13/14) of patients with EGFR 19del mutations had PD-L1 expression $\geq 50 \%$, whereas only $40.0 \%$ of EGFR exon 21 L858R patients (4/10) had PD-L1 $\geq 50 \%(\mathrm{P}=0.009)$. Interestingly, these results suggested that different EGFR mutation types were correlated with different PD-L1 TPS, with the strongest positive PD-L1 expression ( $\geq 50 \%)$ being present in the 19 del mutant subtype.

We subsequently performed a cytologic and bioinformatics analysis of the association of PD-L1 and B3GNT3 expression. A total of $80.8 \%(21 / 26)$ of cases with strong B3GNT3 expression had PD-L $1 \geq 50 \%$; and similarly, $70.0 \%$ (21/30) of PD-L1 $\geq 50 \%$ patients had strong B3GNT3 expression $(\mathrm{P}<0.0001$, Pearson's $\mathrm{r}=0.49)$. Of the patients with PD-L1 >1\%, 79.5\% (31/39) had greater B3GNT3 expression $(2+, 3+)$; whereas of the patients with PD-L1 <1\%, 89.2\% (66/74) had less B3GNT3 expression $(-, 1+)(\mathrm{P}<0.0001$, Pearson's $r=0.37)$. These clinical analyses further confirmed the strong correlation between B3GNT3 and PD-L1.

\section{Prognostic role between the expression of PD-L1 and B3GNT3}

Of the 145 patients with adenocarcinoma, the median follow-up period was 31.7 months, ranging from 2 to 69 months. Expression of PD-L1 and B3GNT3 were assessed in both groups. There was a significant decrease in OS in PD-L $1>1 \%$ patients compared to $\mathrm{PD}-\mathrm{L} 1<1 \%$ patients, especially in the PD-L1 $\geq 50 \%$ group (HR, 1.59; $95 \%$ CI, 1.02-2.48; $\mathrm{P}=0.040)$. The DFS also showed the same tendency in the PD-L1 $\geq 50 \%$ group (HR, $1.71 ; 95 \% \mathrm{CI}$, 1.10-2.66; $\mathrm{P}=0.017$ ) (Figure $\mathrm{S} 1 \mathrm{~A}, \mathrm{~B})$. The median survival time was not reached in every PD-L1 expression subgroup. 


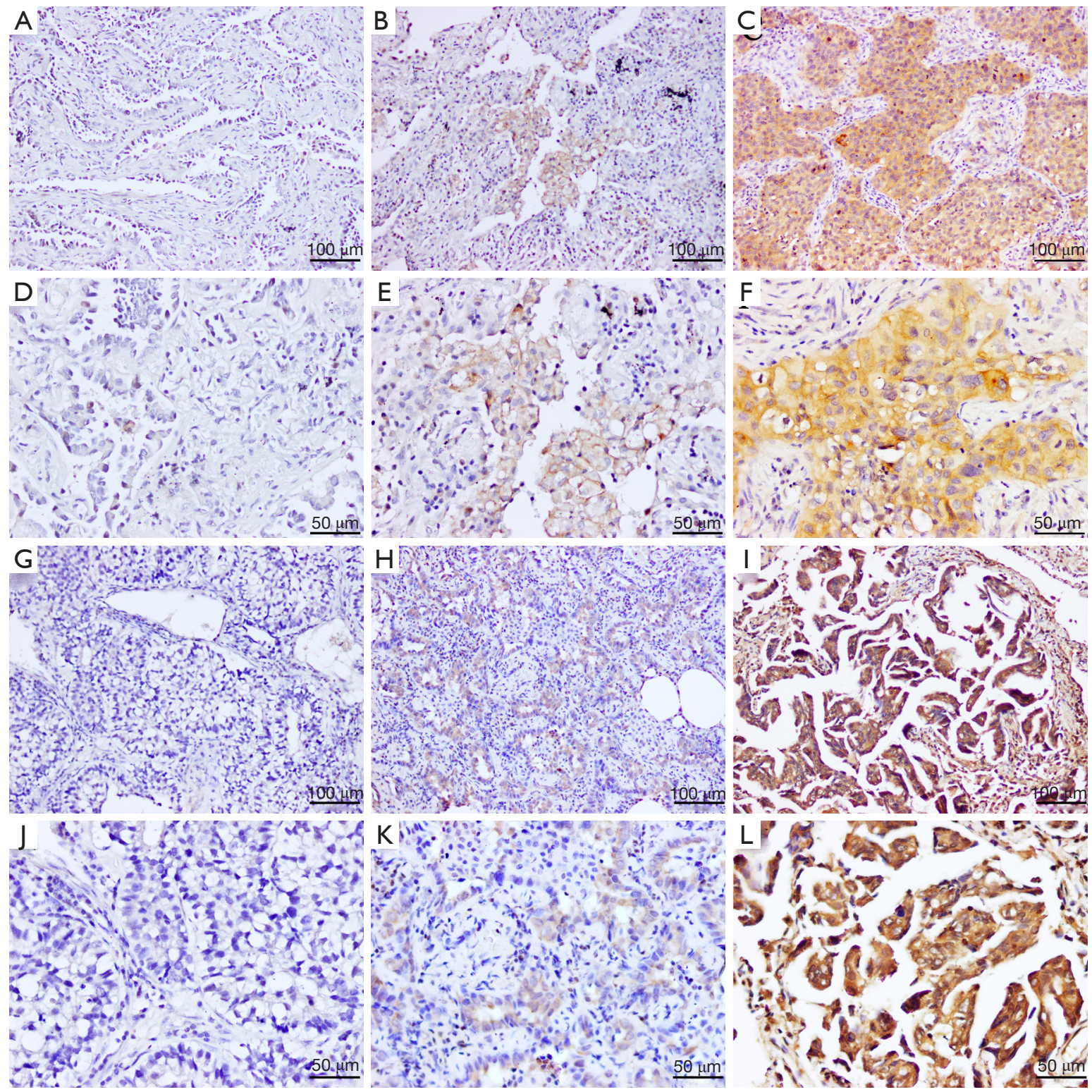

Figure 5 Representative images of immunohistochemical staining for PD-L1 and B3GNT3 in surgically resected tumors from patients with lung adenocarcinoma. (A,D) PD-L1 TPS 0\%. (B,E) PD-L1 TPS 1-49\%. (C,F) PD-L1 TPS $\geq 50 \%$. (G,J) B3GNT3-negative expression, $(\mathrm{H}, \mathrm{K})$ weak B3GNT3 expression, and (I,L) strong B3GNT3 expression. PD-L1, programmed cell death-ligand 1; B3GNT3, beta-1,3-Nacetylglucosaminyltransferase 3; TPS, tumor proportion score. Scale bar: (A-C, G-I) $100 \mu \mathrm{m}$; (D-F, J-L) $50 \mu \mathrm{m}$.

The OS of patients was $76.7 \%(95 \% \mathrm{CI}, 0.62-0.92 \%)$ at 1 year, $70.0 \%$ (95\% CI, $0.55-0.85 \%$ ) at 2 years, and $40.0 \%$ (95\% CI, $0.24-0.56 \%$ ) at 3 years in the PD-L1 $\geq 50 \%$ group. The DFS of patients was $66.7 \%$ (95\% CI, $0.51-0.82 \%)$ at 1 year, $56.7 \%$ (95\% CI, 0.41-0.72) at 2 years, and $30.0 \%$ (95\% CI, $0.13-0.47 \%$ ) at 3 years in the PD-L1 $\geq 50 \%$ group.

The correlation between B3GNT3 immunoreactivity expression and survival was also studied (Figure 6). the results showed statistically significant difference in DFS (logrank $P=0.045$, HR, 0.99; 95\% CI, 0.64-1.54) but not in OS (Figure S1C,D). However, the status of B3GNT3 expression (negative or positive) was not associated with survival in both $\mathrm{OS}(\mathrm{P}=0.213$, HR, 0.55; 95\% CI, 0.22-1.41) and DFS $(\mathrm{P}=0.158, \mathrm{HR}, 0.51 ; 95 \% \mathrm{CI}, 0.20-1.30)$ (Figure 6A,B). Specifically evaluating the non-EGFR mutated subgroup, we observed a significant decrease in OS (HR, 1.61; 95\% CI, 
Table 1 Patient characteristics

\begin{tabular}{|c|c|c|c|c|c|c|}
\hline Characteristic & \multicolumn{3}{|c|}{ PD-L1 ( $n=145)$} & \multicolumn{3}{|c|}{ B3GNT3 $(n=145)$} \\
\hline Age, years, median [range] & $61[40-75]$ & 60 [28-84] & $0.345^{\mathrm{a}}$ & $60[28-84]$ & $62[45-75]$ & $0.279^{a}$ \\
\hline Male:female & $22: 17$ & $17: 60$ & $0.164^{b}$ & $56: 67$ & $12: 10$ & $0.435^{\mathrm{b}}$ \\
\hline Smoking & & & $0.592^{b}$ & & & $0.064^{b}$ \\
\hline No & $29(74.4 \%)$ & $74(69.8 \%)$ & & $91(74.0 \%)$ & $12(54.5 \%)$ & \\
\hline Location & & & $0.869^{b}$ & & & $0.398^{b}$ \\
\hline Left upper lobe & $12(30.8 \%)$ & $40(37.7 \%)$ & & $41(33.3 \%)$ & $11(50.0 \%)$ & \\
\hline Left lower lobe & $6(15.4 \%)$ & $11(10.4 \%)$ & & $14(11.4 \%)$ & $3(13.6 \%)$ & \\
\hline Clinical T stage (AJCC $8^{\text {th }}$ ed.) & & & $0.086^{c}$ & & & $0.104^{c}$ \\
\hline pT1a & $1(2.6 \%)$ & $3(2.8 \%)$ & & $2(1.6 \%)$ & $2(9.1 \%)$ & \\
\hline $\mathrm{pT} 1 \mathrm{~b}$ & $11(28.2 \%)$ & $14(13.2 \%)$ & & $23(18.7 \%)$ & $2(9.1 \%)$ & \\
\hline pT1c & $7(17.9 \%)$ & $16(15.1 \%)$ & & $22(17.9 \%)$ & $1(4.5 \%)$ & \\
\hline pT2a & $12(30.8 \%)$ & $59(55.7 \%)$ & & $59(48.0 \%)$ & $12(54.5 \%)$ & \\
\hline pT2b & $4(10.3 \%)$ & $7(6.6 \%)$ & & $9(7.3 \%)$ & $2(9.1 \%)$ & \\
\hline pT3 & $4(10.3 \%)$ & $5(4.7 \%)$ & & $7(5.7 \%)$ & $2(9.1 \%)$ & \\
\hline TNM stage (AJCC $8^{\text {th }}$ ed.) & & & $0.389^{\circ}$ & & & $0.123^{\mathrm{c}}$ \\
\hline IA1 & $1(2.6 \%)$ & $3(2.8 \%)$ & & $2(1.6 \%)$ & $2(9.1 \%)$ & \\
\hline $\mathrm{IA} 2$ & $11(28.2 \%)$ & $14(13.2 \%)$ & & $23(18.7 \%)$ & $2(9.1 \%)$ & \\
\hline IA3 & $6(15.4 \%)$ & $15(14.2 \%)$ & & $20(16.3 \%)$ & $1(4.5 \%)$ & \\
\hline IB & 8 (20.5\%) & 42 (39.6\%) & & 42 (34.1\%) & $8(36.4 \%)$ & \\
\hline$\| \mathrm{A}$ & $1(2.6 \%)$ & $3(2.8 \%)$ & & $2(1.6 \%)$ & $2(9.1 \%)$ & \\
\hline IIB & $4(10.3 \%)$ & $8(7.5 \%)$ & & $11(8.9 \%)$ & $1(4.5 \%)$ & \\
\hline IIIA & $7(17.9 \%)$ & $17(16.0 \%)$ & & $19(15.4 \%)$ & $5(22.7 \%)$ & \\
\hline IIIB & $1(2.6 \%)$ & $3(2.8 \%)$ & & $3(2.4 \%)$ & $1(4.5 \%)$ & \\
\hline IVA & $0(0.0 \%)$ & $1(0.9 \%)$ & & $1(0.8 \%)$ & $0(0.0 \%)$ & \\
\hline EGFR mutation & & & $0.615^{\mathrm{b}}$ & & & $0.039^{b}$ \\
\hline Yes & $24(61.5 \%)$ & $70(66.0 \%)$ & & $84(68.3 \%)$ & $10(45.5 \%)$ & \\
\hline No & $15(38.5 \%)$ & $36(34.0 \%)$ & & 39 (31.7\%) & $12(54.5 \%)$ & \\
\hline
\end{tabular}

${ }^{\mathrm{a}}$, Wilcoxon test; ${ }^{\mathrm{b}}$, Pearson's chi-Square T test; ${ }^{\mathrm{c}}$, Fisher's exact test. 


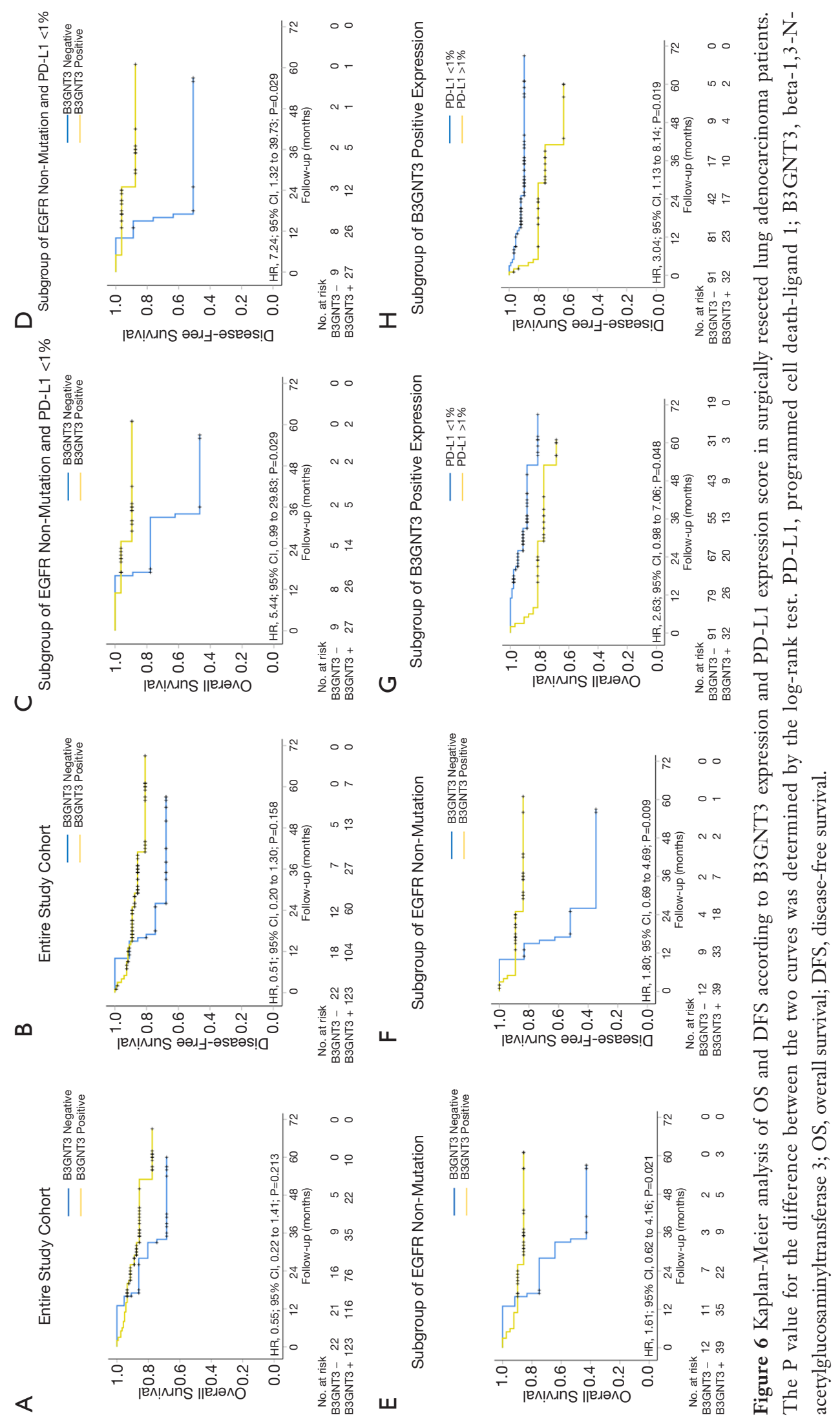


0.62-4.16; $\mathrm{P}=0.021)$ and DFS (HR, 1.80; 95\% CI, 0.69-4.69; $\mathrm{P}=0.009)$ in B3GNT3-negative expression when compared to those with B3GNT3-positive expression (Figure 6E,F). These results indicated that if the patient had no EGFR mutation, B3GNT3-negative expression resulted in a poorer prognosis. When evaluating patients with $\mathrm{PD}-\mathrm{L} 1>1 \%$ staining (1-49\% and $\geq 50 \%$ ), B3GNT3-positive patients had worse clinical outcomes. There was a significant decrease in OS in PD-L1-positive patients, compared to those with a negative expression, in patients with B3GNT3-positive expression (HR, 2.63; 95\% CI, 0.98-7.06; $\mathrm{P}=0.048$ ). DFS also showed the same tendency for patients with both PDL1 and B3GNT3-positive expression (HR, 3.04; 95\% CI, 1.13-8.14; $\mathrm{P}=0.019$ ) (Figure 6G,H). These results indicated that patients with combined PD-L1 >1\% and B3GNT3positive expression experience a worse prognosis in both DFS and OS.

Patients negative for EGFR mutation, B3GNT3-negative expression, and with PD-L1 < $\%$ ("triple negative") had a significant decrease in OS (HR, 5.44; 95\% CI, 0.99-29.83; $\mathrm{P}=0.029)$ and DFS (HR, 7.24; $95 \% \mathrm{CI}, 1.32-39.73$; $\mathrm{P}=0.008$ ) (Figure 6C,D). Although the median OS and DFS were not reached in both groups, The OS of patients was $88.9 \%$ (95\% CI, $0.68-1.10 \%$ ) at 1 year, $77.8 \%$ (95\% CI, $0.51-1.05 \%)$ at 2 years, and $46.7 \%$ (95\% CI, $0.09-0.84 \%$ ) at 3 years in the triple-negative group; while in patients with no EGFR mutation, PD-L1 <1\%, and B3GNT3positive expression, the OS of patients was $96.3 \%(95 \%$ CI, $0.89-1.03 \%$ ) at 1 year, $89.4 \%$ (95\% CI, 0.75-1.04\%) at 2 years, and $89.4 \%$ (95\% CI, $0.75-1.04 \%)$ at 3 years. Furthermore, The DFS of patients was $88.9 \%$ (95\% CI, $0.68-1.10 \%)$ at 1 year, $50.8 \%(95 \%$ CI, $0.16-0.85 \%)$ at 2 years, and $50.8 \%(95 \% \mathrm{CI}, 0.16-0.85 \%)$ at 3 years in the triple-negative group; while in patients with no EGFR mutation, PD-L1 <1\%, and B3GNT3-positive expression, the DFS of patients was $96.3 \%$ (95\% CI, $0.89-1.03 \%)$ at 1 year, $87.5 \%$ (95\% CI, $0.70-1.05 \%)$ at 2 years, and $87.5 \%$ (95\% CI, $0.70-1.05 \%)$ at 3 years. In summary, the results from cytologic experiments and clinical analysis were consistent in demonstrating a close regulatory relationship between PD-L1 and B3GNT3.

\section{Multivariable analyses for patients with PD-L1 and B3GNT3 expression}

Tables 2,3 display the results of univariate and multivariable competing-risk regression analyses for OS and DFS for the patients with PD-L1 and B3GNT3 expression in lung adenocarcinoma. In the final multivariable model, smoking history (HR, 4.43; 95\% CI, 1.29-15.13; $\mathrm{P}=0.018)$ and positive B3GNT3 expression (HR, 3.30; 95\% CI, $1.04-$ 10.50; $\mathrm{P}=0.043$ ) were independent risk factors associated with poor DFS. Additionally, smoking history was the only risk factor associated with poor OS (HR, 4.52; 95\% CI, $1.24-16.43 ; \mathrm{P}=0.022$ ).

\section{Discussion}

In the present study we show biomarker and mutation dependent cancer outcomes in a novel analysis evaluating the impact of EGFR mutation, and PD-L1 and B3GNT3 expression in resected lung adenocarcinoma. Most notably, we show B3GNT3 expression to be an independent variable associated with worse DFS (HR, 3.30; 95\% CI, 1.04-10.50; $\mathrm{P}=0.043)$. We further analyzed B3GNT3 in various subgroups and show worse $O S$ in patients with B3GNT3-positive expression and PD-L1 <1\%, EGFR non-mutated, and both PD-L1 and EGFR non-mutated patients. In fact, patients with "triple negative" cancer (i.e., PD-L1 <1\%, EGFR non-mutated, and B3GNT3 negative) had significantly worse OS (HR, 5.44; 95\% CI, 0.99-29.83; $\mathrm{P}=0.029$ ).

While there is very limited data on B3GNT3 in lung cancer to date, or results are consistent with available reports. For example, Gao et al. showed patients with high B3GNT3 expression had significantly poorer OS $(\mathrm{P}<0.001)$ and DFS $(\mathrm{P}<0.001)$ compared to those with less expression. Its further analysis showed B3GNT3 expression was an independent prognostic factor for OS (HR, 0.383; 95\% CI, 0.249-0.588) and DFS (HR, 0.329; 95\% CI, 0.213-0.508) (17). In the present study, we show that positive B3GNT3 expression was an independent risk factor associated with worse DFS (HR, 3.30; 95\% CI, 1.04-10.50; $\mathrm{P}=0.043$ ), but not OS. This phenomenon was more obviously in $\mathrm{PD}-\mathrm{L} 1$ positive group. No past report has evaluated the rates of EGFR mutations relative to B3GNT3 expression, a novel aspect of our study. In the present study, we found that $89.4 \%$ of EGFR-mutated patients had B3GNT3-positive expression. Additionally, we also show a correlation between PD-L1 expression and B3GNT3. Thus, this study supports B3GNT3 being a novel predictor of survival in lung adenocarcinoma patients.

Another important finding in our study is the potential impact of EGFR mutation and regulation of both PD-L1 and B3GNT3 expression. We found when treated with sub- 
Table 2 Univariate and multivariate analysis of clinicopathological variables for OS in lung adenocarcinoma

\begin{tabular}{|c|c|c|c|c|}
\hline Subgroup & \multicolumn{2}{|c|}{ Univariable analysis } & \multicolumn{2}{|c|}{ Multivariable analysis } \\
\hline \multicolumn{5}{|l|}{ Age } \\
\hline$>60$ years & 1.00 & & 1.00 & \\
\hline$\leq 60$ years & 0.74 (0.32 to 1.70$)$ & 0.472 & $0.43(0.15$ to 1.17$)$ & 0.099 \\
\hline \multicolumn{5}{|l|}{ Sex } \\
\hline Male & 1.00 & & 1.00 & \\
\hline Female & 1.63 (0.69 to 3.81$)$ & 0.262 & 2.57 (0.87 to 7.61$)$ & 0.090 \\
\hline \multicolumn{5}{|l|}{ Smoking } \\
\hline No & 1.00 & & 1.00 & \\
\hline $\mathrm{T} 1 \mathrm{~b}$ & $0.00(0.00$ to 0.00$)$ & 0.983 & 0.00 (0.00 to 0.00$)$ & 0.984 \\
\hline $\mathrm{T} 1 \mathrm{c}$ & 0.20 (0.02 to 2.09$)$ & 0.180 & 0.22 (0.02 to 3.10$)$ & 0.262 \\
\hline $\mathrm{T} 2 \mathrm{a}$ & $0.15(0.01$ to 1.80$)$ & 0.136 & 0.23 (0.01 to 3.70$)$ & 0.298 \\
\hline $\mathrm{T} 2 \mathrm{~b}$ & 0.23 (0.03 to 1.92$)$ & 0.175 & $0.37(0.04$ to 3.80$)$ & 0.401 \\
\hline T3 & 1.07 (0.12 to 9.65$)$ & 0.953 & 2.94 (0.21 to 40.71$)$ & 0.421 \\
\hline $\mathrm{T} 4$ & 3.15 (0.37 to 26.72$)$ & 0.294 & $9.48(0.72$ to 125.41$)$ & 0.088 \\
\hline \multicolumn{5}{|c|}{ Pathological N stage } \\
\hline Positive & $1.82(0.71$ to 4.66$)$ & 0.213 & 2.22 (0.64 to 7.69$)$ & 0.206 \\
\hline
\end{tabular}

lethal gefitinib, PD-L1 and B3GNT3 mRNA to decrease in HCC827 and PC9 EGFR mutated cell lines. Interestingly, this did not occur in the EGFR wild-type A549 cell lines treated with sub-lethal dosing of gefitinib. In accordance with these results, Akbay and colleagues (20) found a correlation between the activation of EGFR signaling and a signature of immunosuppression which manifested as PD-L1 upregulation, cytotoxic T lymphocyte antigen-4 (CTLA-4) increase, and the emergence of multiple tumorpromoting inflammatory cytokines. They also demonstrated that gefitinib treatment did not decrease PD-L1 levels in the gefitinib-resistant H1975 and PC9 cell lines. Our results showed a similar correlation between PD-L1 and EGFR mutation, as an EGFR-TKI-resistant cell line, H1975 was also found to have a high PD-L1 expression in our study. This is corroborated by past research showing PD-L1 expression to be upregulated through the EGFR T790M mutation which promotes immune escape in NSCLC (21). Taken together, these findings suggest that the regulatory mechanisms of PD-L1 expression may vary across the different subtypes of NSCLC cell lines, such as EGFR mutation and EGFR wild type.

Other researchers have reported that the downregulation to B3GNT3 may modulate PD-L1 expression in triplenegative breast cancer (16). Furthermore, EGFR was shown to stabilize PD-L1 via glycogen synthase kinase $3 \beta$ 
Table 3 Univariate and multivariate analysis of clinicopathological variables for DFS in lung adenocarcinoma

\begin{tabular}{|c|c|c|c|c|}
\hline Subgroup & \multicolumn{2}{|c|}{ Univariable analysis } & \multicolumn{2}{|c|}{ Multivariable analysis } \\
\hline \multicolumn{5}{|l|}{ Age } \\
\hline$>60$ years & 1.00 & & 1.00 & \\
\hline$\leq 60$ years & 0.69 (0.30 to 1.61$)$ & 0.401 & $0.40(0.15$ to 1.08$)$ & 0.069 \\
\hline Male & 1.00 & & 1.00 & \\
\hline Female & 1.69 (0.72 to 3.95$)$ & 0.228 & 2.43 (0.77 to 7.65$)$ & 0.129 \\
\hline \multicolumn{5}{|l|}{ Smoking } \\
\hline No & 1.00 & & 1.00 & \\
\hline \multicolumn{5}{|c|}{ Pathological T stage } \\
\hline $\mathrm{T} 1 \mathrm{~b}$ & 0.00 (0.00 to 0.00$)$ & 0.975 & 0.00 (0.00 to 0.00$)$ & 0.976 \\
\hline $\mathrm{T} 1 \mathrm{c}$ & 0.18 (0.02 to 1.72$)$ & 0.135 & 0.18 (0.01 to 2.32$)$ & 0.190 \\
\hline $\mathrm{T} 2 \mathrm{a}$ & 0.14 (0.01 to 1.54$)$ & 0.107 & 0.17 (0.01 to 2.53$)$ & 0.200 \\
\hline $\mathrm{T} 2 \mathrm{~b}$ & 0.15 (0.02 to 1.24$)$ & 0.078 & $0.18(0.02$ to 1.78$)$ & 0.144 \\
\hline T3 & 0.81 (0.09 to 7.30$)$ & 0.853 & $2.13(0.16$ to 27.99$)$ & 0.565 \\
\hline $\mathrm{T} 4$ & 2.37 (0.28 to 20.12$)$ & 0.429 & $6.18(0.50$ to 76.07$)$ & 0.155 \\
\hline \multicolumn{5}{|c|}{ Pathological N stage } \\
\hline Positive & 1.97 (0.77 to 5.04$)$ & 0.158 & $3.30(1.04$ to 10.50$)$ & 0.043 \\
\hline
\end{tabular}

inactivation in basal-like breast cancer (15). These results confirm the association of glycosylation pathways with the regulation of $\mathrm{PD}-\mathrm{L} 1$, which may be a clue to enhancing the efficacy of potential immune therapy. However, no study has examined the connection between B3GNT3 and PD-L1 expression in NSCLC cell lines treated with EGFR-TKIs. We showed that B3GNT3 was specifically upregulated in three EGFR-mutated NSCLC cell lines (H1975, HCC827, and PC9), and a strong correlation between B3GNT3 and EGFR gene mutation was also observed. We further found that PD-L1 and B3GNT3 expression levels were significantly decreased after the intervention of EGFR inhibitor. This is consistent with research from $\mathrm{Li}$ and colleagues (15), which found that in order to identify the upstream growth factor signaling that governs PD-L1 stabilization, only EGFR can strongly induce PD-L1 expression. Other EGF ligands such as epiregulin, transforming growth factor alpha (TGF $\alpha$ ) and heparin-binding EGF, also participated in the induction of PD-L1 expression. In another study, PD-L1 and PD-1 interaction was demonstrated to be modulated specifically by N-linked glycosylation; using TCGA bioinformatics analysis, the researchers also discovered that B3GNT3 was positively correlated with EGFR in basal-like breast cancer. Its further analysis showed a strong correlation between B3GNT3 and EGFR gene expression, and subsequent mass spectrometry for protein identification identified B3GNT3 as a PD-L1- 
interacting protein. Their conclusion that B3GNT3 binds to PD-L1 (16) further supports the notion that B3GNT3 is involved in PD-L1 regulation, and this is in line with our results.

EGFR-TKIs are standard first-line therapy for metastatic lung adenocarcinoma with TKI-sensitive EGFR mutations. However, in recent years, breakthroughs in inhibitors of PD-1 and PD-L1 have rapidly changed the therapeutic model of NSCLC $(22,23)$. There is controversy regarding the prognostic utility of using TPS classification of PDL1 on the efficacy of first-line EGFR-TKIs in EGFRmutated lung adenocarcinoma patients. Peng et al. showed no statistical differences observed among the TPS $<1 \%$, TPS $1-49 \%$, and TPS $\geq 50 \%$ groups in objective response rate (ORR) $(68.9 \%$ vs. $62.2 \%$ vs. $73.1 \%, \mathrm{P}=0.807)$, or the median OS (21.27 vs. 20.63 vs. 19.43 months, $\mathrm{P}=0.77$ ) (24). However, Yang et al. reported that PD-L $1<50 \%$ was an independent prognostic factor for longer PFS in patients who were treated with EGFR-TKIs (HR, 0.433; 95\% CI: $0.250-0.751, \mathrm{P}=0.003)(25)$. While not recommended as first-line therapy, PD-L1/PD-1 blockade is considered as an alternative for patients with acquired resistance to EGFRTKIs (26). New biomarkers related to immune checkpoint inhibitors are urgently needed in order to improve the efficacy of PD-1/PD-L1 blockade in patients both with and without EGFR mutations.

B3GNT3 is a type II transmembrane protein in the Golgi apparatus, and contributes to the regulation of L-selectin ligand function, lymphocyte trafficking, and T cell homing $(27,28)$. B3GNT3 is overexpressed in the breast cancer (29), and also plays a critical role in the aggressiveness of pancreatic cancer (30). Elevated B3GNT3 expression is also associated with pelvic lymph node metastasis and poor outcomes in early-stage cervical cancer patients (31). Immunotherapy can confer excellent survival benefits of long-term efficacy and lower toxicity for NSCLC patients $(22,32,33)$. Despite this, some clinical trials shown that patients in EGFR mutation subgroups were unable to receive benefit from immunotherapy $(32,34)$. One explanation for this was that the immunotherapy in these patients might have precipitated hyperprogressive disease, leading to high-grade toxicity (35). Thus, it is still controversial whether the combination of related signatures and a rational combination of PD-1/PD-L1 inhibitors and EGFR-TKIs can improve OS or DFS. In our research, we observed a significant decrease in both DFS and OS in PD-L1 >1\% patients compared to PD-L1 $<1 \%$ patients, especially in the PD-L $1 \geq 50 \%$ group. Further investigation showed that patients with PD-L1 >1\% and B3GNT3-positive expression might have experienced even worse prognosis in both DFS and OS. However, the survival varied when the mixed EGFR status was observed. Although, 89.4\% (84/94) of EGFR-mutated patients had B3GNT3-positive expression and $80.8 \%$ of PD-L $1 \geq 50 \%$ patients $(21 / 26)$ had strong B3GNT3 expression, only the triple-negative group (no EGFR mutation, PD-L1 <1\%, and B3GNT3-negative expression) showed a significant decrease in OS and DFS. These results may serve as a reference for future prognosis evaluation and immunotherapy selection.

Limitations to this research should be acknowledged. First, although our study suggests the prognostic significance of B3GNT3 in patients with lung adenocarcinoma and suggest the relationship between B3GNT3, PD-L1 expression, and $E G F R$ mutations, the results are derived from the retrospective data of a single center. They cannot wholly represent the overall population, and the possibility of bias cannot be ruled out. The sample size for retrospective analysis is still small, and the number of research cases will be further expanded in future studies. Secondly, only one antibody was selected for PD-L1 immunohistochemistry. Different antibodies may vary in in PD-L1 expression (36), and thus multiple antibodies should be introduced for simultaneous verification in future studies. Finally, although bioinformatics analysis, clinical samples, and cytological experiments were able to confirm a correlation between the expression of B3GNT3 and PD-L1 in EGFR-mutated patients, we still lack in-depth research concerning the potential mechanism. This should be the subject of future exploration.

\section{Conclusions}

Our results confirmed B3GNT3 as a novel maker for predicting the prognostic outcome of lung adenocarcinoma. PD-L1 TPS is closely related to B3GNT3 expression and EGFR mutation status, and might be one of the factors worth considering in the future treatment of immunotherapy. The multiple mechanisms of dynamic immune profiles, PD-L1 expression changes during treatment, and varied tumor mutational burdens might have contributed to discrepancies in data regarding the correlation among B3GNT3 expression, PD-L1 TPS, and EGFR mutation status. Further studies are needed to clarify and identify the potential prognostic and therapeutic biomarkers related to anti-PD-1/PD-L1 treatment in this special lung adenocarcinoma subpopulation with $E G F R$ mutation and positive B3GNT3 expression. 


\section{Acknowledgments}

The authors appreciate the academic support from AME Lung Cancer Collaborative Group.

Funding: This work was supported by the National Natural Science Foundation Project (NSFC 81602025 to Dr. Mei).

\section{Footnote}

Reporting Checklist: The authors have completed the REMARK reporting checklist. Available at http://dx.doi. org/10.21037/tlcr-21-146

Data Sharing Statement: Available at http://dx.doi. org/10.21037/tlcr-21-146

Conflicts of Interest: All authors have completed the ICMJE uniform disclosure form (available at http://dx.doi. org/10.21037/tlcr-21-146). Dr. GM serves as an unpaid editorial board member of Translational Lung Cancer Research from Jul 2019 to Jul 2021. The other authors have no conflicts of interest to declare.

Ethical Statement: The authors are accountable for all aspects of the work in ensuring that questions related to the accuracy or integrity of any part of the work are appropriately investigated and resolved. The study was approved by the Institutional Review Board of West China Hospital and was conducted in accordance with the guidelines of the Helsinki Declaration (as revised in 2013). Individual consent for this retrospective analysis was waived.

Open Access Statement: This is an Open Access article distributed in accordance with the Creative Commons Attribution-NonCommercial-NoDerivs 4.0 International License (CC BY-NC-ND 4.0), which permits the noncommercial replication and distribution of the article with the strict proviso that no changes or edits are made and the original work is properly cited (including links to both the formal publication through the relevant DOI and the license). See: https://creativecommons.org/licenses/by-nc-nd/4.0/.

\section{References}

1. Miller KD, Nogueira L, Mariotto AB, et al. Cancer treatment and survivorship statistics, 2019. CA Cancer J Clin 2019;69:363-85.

2. Reck M, Rodriguez-Abreu D, Robinson A, et al. Updated
Analysis of KEYNOTE-024: Pembrolizumab Versus Platinum-Based Chemotherapy for Advanced Non-SmallCell Lung Cancer With PD-L1 Tumor Proportion Score of 50\% or Greater. J Clin Oncol 2019;37:537-46.

3. Zhao D, Chen X, Qin N, et al. The prognostic role of EGFR-TKIs for patients with advanced non-small cell lung cancer. Sci Rep 2017;7:40374.

4. Sequist LV, Martins RG, Spigel D, et al. First-line gefitinib in patients with advanced non-small-cell lung cancer harboring somatic EGFR mutations. J Clin Oncol 2008;26:2442-9.

5. Dong H, Strome S, Salomao D, et al. Tumor-associated B7-H1 promotes T-cell apoptosis: a potential mechanism of immune evasion. Nat Med 2002;8:793-800.

6. Ribas A. Releasing the Brakes on Cancer Immunotherapy. N Engl J Med 2015;373:1490-2.

7. Kerr KM, Nicolson MC. Non-Small Cell Lung Cancer, PD-L1, and the Pathologist. Arch Pathol Lab Med 2016;140:249-54.

8. Rittmeyer A, Barlesi F, Waterkamp D, et al. Atezolizumab versus docetaxel in patients with previously treated non-smallcell lung cancer (OAK): a phase 3, open-label, multicentre randomised controlled trial. Lancet 2017;389:255-65.

9. Herbst RS, Baas P, Kim DW, et al. Pembrolizumab versus docetaxel for previously treated, PD-L1-positive, advanced non-small-cell lung cancer (KEYNOTE-010): a randomised controlled trial. Lancet 2016;387:1540-50.

10. Gainor JF, Shaw AT, Sequist LV, et al. EGFR Mutations and ALK Rearrangements Are Associated with Low Response Rates to PD-1 Pathway Blockade in Non-Small Cell Lung Cancer: A Retrospective Analysis. Clin Cancer Res 2016;22:4585-93.

11. Lisberg A, Cummings A, Goldman J, et al. A Phase II Study of Pembrolizumab in EGFR-Mutant, PD-L1+, Tyrosine Kinase Inhibitor Naïve Patients With Advanced NSCLC. J Thorac Oncol 2018;13:1138-45.

12. Hennet T, Dinter A, Kuhnert P, et al. Genomic cloning and expression of three murine UDP-galactose: beta-Nacetylglucosamine beta1,3-galactosyltransferase genes. J Biol Chem 1998;273:58-65.

13. Yeh JC, Hiraoka N, Petryniak B, et al. Novel sulfated lymphocyte homing receptors and their control by a Core 1 extension beta 1,3-N-acetylglucosaminyltransferase. Cell 2001;105:957-69.

14. Mitoma J, Petryniak B, Hiraoka N, et al. Extended core 1 and core 2 branched O-glycans differentially modulate sialyl Lewis X-type L-selectin ligand activity. J Biol Chem 2003;278:9953-61. 
15. Li CW, Lim SO, Xia W, et al. Glycosylation and stabilization of programmed death ligand-1 suppresses T-cell activity. Nature communications 2016;7:12632.

16. Li CW, Lim SO, Chung EM, et al. Eradication of TripleNegative Breast Cancer Cells by Targeting Glycosylated PD-L1. Cancer Cell 2018;33:187-201.e10.

17. Gao L, Zhang H, Zhang B, et al. B3GNT3 overexpression is associated with unfavourable survival in non-small cell lung cancer. J Clin Pathol 2018;71:642-7.

18. Roach C, Zhang N, Corigliano E, et al. Development of a Companion Diagnostic PD-L1 Immunohistochemistry Assay for Pembrolizumab Therapy in Non-Small-cell Lung Cancer. Appl Immunohistochem Mol Morphol 2016;24:392-7.

19. Ho WL, Che MI, Chou CH, et al. B3GNT3 expression suppresses cell migration and invasion and predicts favorable outcomes in neuroblastoma. Cancer Sci 2013;104:1600-8.

20. Akbay EA, Koyama S, Carretero J, et al. Activation of the PD-1 pathway contributes to immune escape in EGFRdriven lung tumors. Cancer Discov 2013;3:1355-63.

21. Peng S, Wang R, Zhang X, et al. EGFR-TKI resistance promotes immune escape in lung cancer via increased PDL1 expression. Mol Cancer 2019;18:165.

22. Mok TSK, Wu YL, Kudaba I, et al. Pembrolizumab versus chemotherapy for previously untreated, PD-L1expressing, locally advanced or metastatic non-small-cell lung cancer (KEYNOTE-042): a randomised, open-label, controlled, phase 3 trial. Lancet 2019;393:1819-30.

23. Reck M, Rodriguez-Abreu D, Robinson AG, et al. Updated Analysis of KEYNOTE-024: Pembrolizumab Versus Platinum-Based Chemotherapy for Advanced NonSmall-Cell Lung Cancer With PD-L1 Tumor Proportion Score of 50\% or Greater. J Clin Oncol 2019;37:537-46.

24. Hsu PC, Wang CW, Kuo SCH, et al. The Co-Expression of Programmed Death-Ligand 1 (PD-L1) in Untreated EGFR-Mutated Metastatic Lung Adenocarcinoma. Biomedicines 2020;8:36.

25. Yang CY, Liao WY, Ho CC, et al. Association between programmed death-ligand 1 expression, immune microenvironments, and clinical outcomes in epidermal growth factor receptor mutant lung adenocarcinoma patients treated with tyrosine kinase inhibitors. Eur J Cancer 2020;124:110-22.

26. Lisberg A, Cummings A, Goldman JW, et al. A Phase II Study of Pembrolizumab in EGFR-Mutant, PD-L1+, Tyrosine Kinase Inhibitor Naive Patients With Advanced NSCLC. J Thorac Oncol 2018;13:1138-45.

27. Hennet T, Dinter A, Kuhnert P, et al. Genomic cloning and expression of three murine UDP-galactose: beta-N- acetylglucosamine beta1,3-galactosyltransferase genes. J Biol Chem 1998;273:58-65.

28. Yeh JC, Hiraoka N, Petryniak B, et al. Novel sulfated lymphocyte homing receptors and their control by a Core1 extension beta $1,3-\mathrm{N}$-acetylglucosaminyltransferase. Cell 2001;105:957-69.

29. Shiraishi N, Natsume A, Togayachi A, et al. Identification and characterization of three novel beta 1,3-N-acetylglucosaminyltra nsferases structurally related to the beta 1,3 -galactosyltransferase family. J Biol Chem 2001;276:3498-507.

30. Barkeer S, Chugh S, Karmakar S, et al. Novel role of O-glycosyltransferases GALNT3 and B3GNT3 in the self-renewal of pancreatic cancer stem cells. BMC Cancer 2018;18:1157.

31. Zhang W, Hou T, Niu C, et al. B3GNT3 Expression Is a Novel Marker Correlated with Pelvic Lymph Node Metastasis and Poor Clinical Outcome in Early-Stage Cervical Cancer. PLoS One 2015;10:e0144360.

32. Lee CK, Man J, Lord S, et al. Clinical and Molecular Characteristics Associated With Survival Among Patients Treated With Checkpoint Inhibitors for Advanced NonSmall Cell Lung Carcinoma: A Systematic Review and Meta-analysis. JAMA Oncol 2018;4:210-6.

33. Herbst RS, Baas P, Kim DW, et al. Pembrolizumab versus docetaxel for previously treated, PD-L1-positive, advanced non-small-cell lung cancer (KEYNOTE-010): a randomised controlled trial. Lancet 2016;387:1540-50.

34. Azuma K, Ota K, Kawahara A, et al. Association of PDL1 overexpression with activating EGFR mutations in surgically resected nonsmall-cell lung cancer. Ann Oncol 2014;25:1935-40.

35. Soo RA, Lim SM, Syn NL, et al. Immune checkpoint inhibitors in epidermal growth factor receptor mutant non-small cell lung cancer: Current controversies and future directions. Lung Cancer 2018;115:12-20.

36. Udall M, Rizzo M, Kenny J, et al. PD-L1 diagnostic tests: a systematic literature review of scoring algorithms and test-validation metrics. Diagn Pathol 2018;13:12.

(English Language Editor: J. Gray)

Cite this article as: Leng $\mathrm{X}$, Wei S, Mei J, Deng S, Yang Z, Liu Z, Guo C, Deng Y, Xia L, Cheng J, Zhao K, Gan F, Li C, Merrell KW, Molina JR, Metro G, Liu L. Identifying the prognostic significance of B3GNT3 with PD-L1 expression in lung adenocarcinoma. Transl Lung Cancer Res 2021;10(2):965980. doi: $10.21037 /$ tlcr-21-146 
A

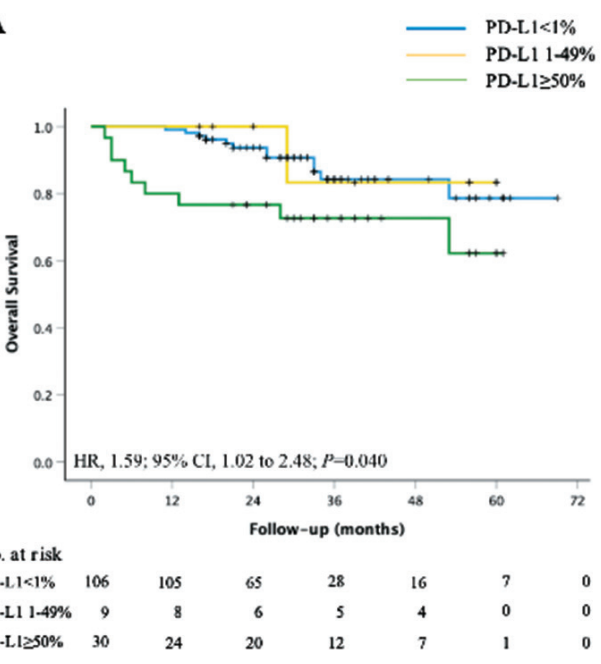

C

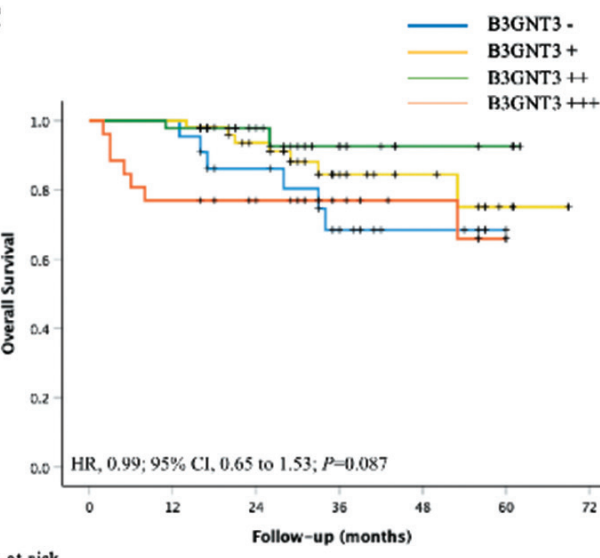

B
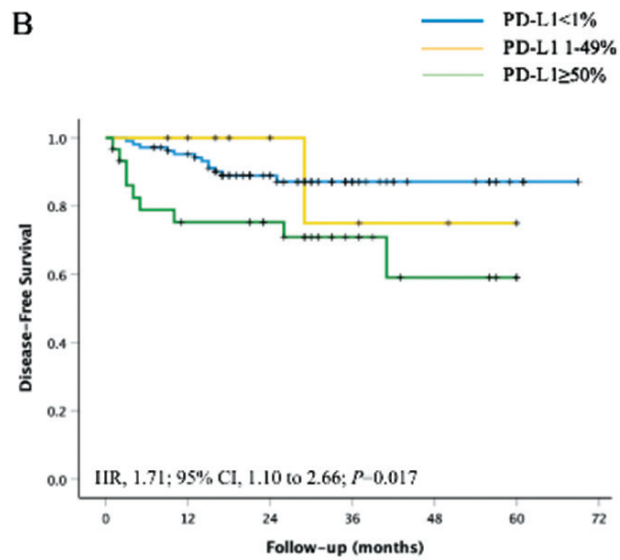

No. at risk

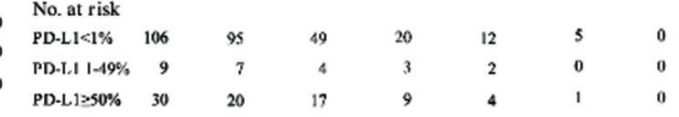

D
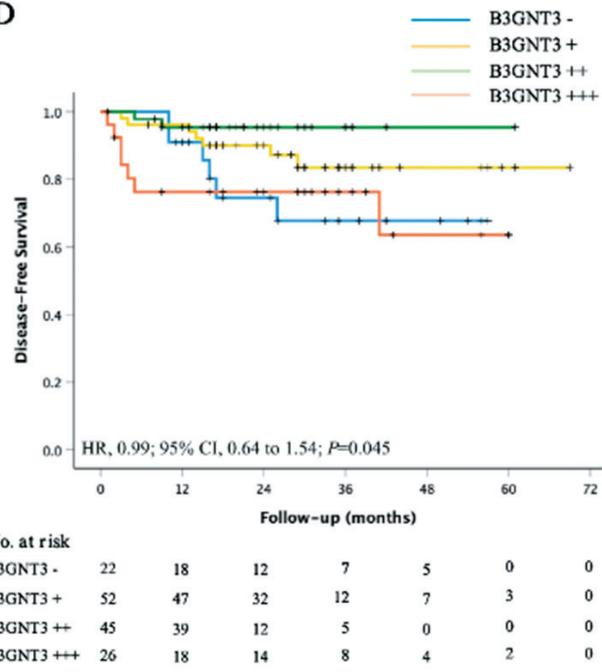

Figure S1 Kaplan-Meier analysis of OS and DFS according to PD-L1 expression score (TPS $<1$, TPS $1-49 \%$, TPS $\geq 50 \%$ ) (A,B) and B3GNT3 expression $(-,+,++,+++)(\mathrm{C}, \mathrm{D})$ in surgically resected lung adenocarcinoma patients. The $\mathrm{P}$ value for the difference between the two curves was determined by the log-rank test. PD-L1, programmed cell death-ligand 1; B3GNT3, beta-1,3-Nacetylglucosaminyltransferase 3; OS, overall survival; DFS, disease-free survival. 